\title{
Two exercises as trait anxiety mitigating factors
}

\author{
Rasoul Karbalaee Shirifard ${ }^{1}$ and Habib Honari ${ }^{2}$ \\ ${ }^{1}$ Philosophy and Psychology Department, Yerevan State University, Armenia \\ ${ }^{2}$ Physical Education Department, Psychology and Educational Science College, Allameh Tabatabaee University, \\ Republic Islamic of Iran \\ rksh50@yahoo.com ${ }^{1}$; honari_h@yahoo.com²
}

\begin{abstract}
This study investigated the influence of eight-week bodily fitness and aerobic exercise interventions on psychological health of youths. The first 52-persons from 110 subjects who were more anxious than others were determined. Subjects $(\mathrm{M}$ age $=20.28,6 ; \mathrm{N}=52)$ were randomly assigned to one of three groups: bodily fitness, and aerobic and non experimental group. Classes met 1 hour, 3 days per week, for 8 weeks. Trait Anxiety scale of Spielberger was used to the individual. Pre and post-test were used to the test and non experimental groups. Findings were analysed with ANOVA and it revealed decreases in trait anxiety over the intervention. Both groups benefited from the physical exercise intervention and there was no difference between the two groups. Physical exercise is of key importance to mitigating youth trait anxiety.
\end{abstract}

Keywords: Trait anxiety, Bodily fitness, Aerobic exercise, Youth.

\section{Introduction}

Anxiety is generally described as human emotions and trait anxiety is constant during a person's life. Anxiety can be a product of biological factors, environmental, social, and genetic. Poor nutrition, lack of sleep, drug abuse, and physical changes can create anxiety. Environmental changes can also trigger anxiety. Young people entering to university are experiencing a new atmosphere. Among the age groups, young people should try to build their lives but the trait anxiety often decreases their quality of life. One view defines anxiety as "a future-oriented mood state in which one is ready or prepared to attempt to cope with upcoming negative events (Barlow \& David, 2002). A common distinction in this literature is between state and trait questionnaire measures of anxiety. Trait anxiety is the general predisposition to respond across many situations with high levels of anxiety. State anxiety, on the other hand, is much more specific and refers to the person's anxiety at a particular moment. Although "trait" and "state" aspects of anxiety are conceptually distinct, the available operational measures show a considerable amount of overlap among these subcomponents of anxiety (Smith, 1989). Anxious individuals are referred to clinical psychologists or psychotherapists and psychiatrists, they are consulting. Some of them take various drugs and more techniques until they can live better. They suffer from their pain but sometimes they don't get good result. Exercises can help our youth that stay healthy and strong and be ready for better life. Physical activity is associated with a range of health benefits, and its absence can have harmful effects on health and well being, increasing the risk for coronary heart disease, diabetes, certain cancers, obesity, hypertension and all cause mortality (CDC, 1996). This study is focused on those benefits which are individual psychological aspects in nature. The present investigation was designed whether physical exercise reduces the trait anxiety rates of the youth.

\section{Models of qualifier the profit of exercise}

Several models of psychosocial and psychological profit of exercises have been raised. One of them is Endorphin hypothesis, at present, the hypothesis that endorphin is produced by exercise leads to a change of mood are to be plausible. The influence of acute exercise on psychological well-being, in particular 'euphoria', is caused by the release and subsequent binding of endogenous opiate, these being -endorphins to receptor sites in the brain (Steinberg \& Sykes, 1985). Other psychological theory is Self-esteem; there are models that try to explain the relationship between self-esteem and physical exercises. These models have focused on increasing awareness of the body, strengthen the mind, increase your confidence and prosperity, enhance social relationships, reduce anxiety are the benefits of physical exercise. One such model is Sonstroem's (1978) psychological model for physical activity and another factor is distraction hypothesis, Distraction hypothesis implies man's attention to something other than anxiety, and this can anxiety be reduced. We can find it in conceptualization by Bahrke \& Morgan, (1978) it compared the effects on state anxiety of walking on a treadmill, meditating or resting in a comfortable chair. Instructions and methods

With regard to this investigation, youth students from 5 different departments in Allameh Tabatabaee university, different Faculty were used and teaching students primary(1,2 years) base with no previous training, who were accidental and evenly assigned to engage in one of two treatments for 8 weeks. Trait Anxiety scale and a demographic questioner were used on 110 youth. The first 52 subjects that had the High rates of trait anxiety were assigned. Students participated in two group's test and the one group was chosen as the 
non experimental group. Initial test and final test was performed on both the test groups and non experimental group. Findings were analyzed by ANOVA and Test groups examined in organized physical exercises such as bodily fitness, and aerobic. The findings indicated the use of exercises as a strategy for improved coping with trait anxiety. Statistical of descriptive was determined for each group. For testing of the variance analysis, 0.05 significance rate was chosen. Participants

Table1. Participants' $(N=68)$ Demographics

\begin{tabular}{|c|c|c|c|c|c|}
\hline \multicolumn{6}{|c|}{ Statistics } \\
\hline $\mathrm{N}: 52$ & Age & \multirow{2}{*}{ Factor } & \multirow{2}{*}{ Category } & \multirow{2}{*}{$\mathrm{F}$} & \multirow{2}{*}{$\%$} \\
\hline Mean & 20.28 & & & & \\
\hline Median & 20 & \multirow{5}{*}{$\begin{array}{l}\text { Gender } \\
\text { Marital Status }\end{array}$} & Female & 33 & 63.5 \\
\hline Mode & 23 & & Male & 19 & 36.5 \\
\hline Std. & 190 & & Single & 35 & 67.3 \\
\hline Deviation & 1.90 & & Married & 12 & 23.1 \\
\hline Minimum & 17.80 & & Divorced & 5 & 9.6 \\
\hline \multirow{6}{*}{ Maximum } & \multirow{6}{*}{24} & \multirow{6}{*}{$\begin{array}{l}\text { Occupation } \\
\text { status } \\
\text { Collage }\end{array}$} & Part-time Work & 17 & 32.7 \\
\hline & & & Psychology & 15 & 28.8 \\
\hline & & & Literature & 14 & 26.9 \\
\hline & & & Management & 7 & 13.5 \\
\hline & & & Political & 8 & 15.4 \\
\hline & & & Council & 8 & 15.4 \\
\hline
\end{tabular}

Participants were youth individuals (ages 17.8 to 24; $M=20.28, S D=1.90)$ from 5 colleges of Allameh Tabatabaee University (Table 1). Participants at end were 52 youths (intervention group, $n_{-} 34$; control group, $n_{-}$ 18). Gender distribution was, Male students constituted $34.6 \%\left(n_{-} 19\right)$ and $63.4 \%\left(n_{-} 33\right)$ were female. Marital status was $67.3 \%\left(n \_35\right)$ for singles and $23.1 \%$ (n_12) married and a minority of the youth reported that they were divorced $9.6 \%$ and $(n+5)$. Occupation distribution was, part-time work students constituted $32.7 \%\left(n_{-} 17\right)$ and $67.3 \%\left(n \_35\right)$ for no job students. Participants were from 5 collages: Psychology 28.8\% $(n \ldots 15)$, Literature $26.9 \%(n-14)$, Management $13.5 \%(n-7)$ and for Political $15.4 \%(n+8)$ and the end was Council 15.4\% ( $n$ _ 8). Subjects were 52 youth individuals and divided in 3 groups: Control Group18 persons, Bodily Fitness 17 persons and for aerobic program 17 persons. According to the test result, 52 student of 110 persons who got highest trait anxiety scores were chosen as research group. Some of research group (34) accepted as exercise group. Female and male student's ratios were almost same, and it was equal in exercise group (Table 2 \& Table 3).

Instrumentations

A demographic questionnaire and the trait Anxiety

Table 2 shows these dispersion 3 groups

\begin{tabular}{|l|c|c|}
\hline \multicolumn{3}{|c|}{3 Groups } \\
\hline \multicolumn{1}{|c|}{ Groups } & $\mathrm{F}$ & $\%$ \\
\hline Control group & 18 & 34.6 \\
\hline Bodily fitness & 17 & 32.7 \\
\hline Aerobic & 17 & 32.7 \\
\hline Total & 52 & 100.0 \\
\hline
\end{tabular}

scale were used. The demographic questionnaire includes age, gender, marital status, occupational status, and their college. The STAI is a 40-item inventory, which measures both state (how an individual feels at a particular moment in time) and trait (how an individual generally feels) anxiety. The original State-Trait Anxiety scale was developed by Spielberger (Spielberger et al., 1970). The present version of the STAI was revised in 1983. The STAI has two parts: the State Anxiety scale (SAl) and the Trait Anxiety scale (TAl). The former part measures situational anxiety whiles the latter measures baseline anxiety; each part consists of 20 items. These items are rated on a 4-point scale, with a higher score equating to a greater anxiety level. According to studies by Spielberger et al. (1970), the test retest correlation for the TAl is higher than that for the SAI. Despite the fluctuating test-retest correlations of the SAI, which reflect its validity in measuring state anxiety, the internal consistency of the SAI, as measured by the Cronbach's alpha score, has been found to be high. At this investigation we used trait anxiety scale for examined anxiety in course of education in university. Bodily fitness, the fitness intervention was chosen based on the lesson project of university of Allameh Tabatabaee. Each bodily fitness session began with a 10 minute warm-up and ended with a 10 minute cool-down. Therefore, a fitness class which focused on strength and balance activities was implemented as one of the exercise interventions.

Title of plane: Bodily fitness, Warm-up:10 minutes, Bodybuilding: 20 minutes, Stationery exercises: 20 minutes, Cold-down: 10 minutes, Goal of exercise: ascending of 5 factors of bodily fitness: 1: speed 2: power 3: resistance 4: agility 5 : flexibility.

Aerobic exercise is physical exercise of relatively low intensity that depends primarily on the aerobic energygenerating process. Generally, light-to-moderate intensity activities that are sufficiently supported by aerobic metabolism can be performed for extended periods of time (Sharon et al., 2007).

A control group (non-exercise control) for the intervention was selected as a control without physical activity.

\section{Procedure}

Measurements were conducted pre-intervention, with the participants filling out the entire tests, the trait measures (trait TAl).demographic data (including age, gender, occupational status, marital status, and current collage) were collected. Eventually after eight weeks of intervention, measurement was conducted, with individuals completing the entire of measures (trait TAl). Data analysis

Data were analyzed with SPSS software. Descriptive statistics were diagnosed for the demographic information. The first hypothesis was examined that there is a significant difference between mean of experimental and control groups at the beginning of experimental
Sci.Technol.Edu.

Clndian Society for Education and Environment (iSee)
"Exercise for trait anxiety mitigation" http://www.indjst.org
R.K.Shirifard \& H.Honari Indian J.Sci.Technol. 
Table 3. The dispersion of Investigation gender group

\begin{tabular}{|c|c|c|c|c|c|c|}
\hline Investigation Group & \multicolumn{2}{|c|}{ Female } & \multicolumn{2}{|c|}{ Male } & \multicolumn{2}{|c|}{ Total } \\
\hline & Number & $\%$ & Number & $\%$ & Number & $\%$ \\
\hline $\begin{array}{l}\text { Non experimental } \\
\text { Group }\end{array}$ & 10 & 55.6 & 8 & 44.4 & 18 & 100,0 \\
\hline Exercise Group & 23 & 67.6 & 11 & 32.4 & 34 & 100,0 \\
\hline TOTAL & & & & & 52 & 100.0 \\
\hline
\end{tabular}

research, with using analysis of variance. The second hypothesis, through analysis of variance test for independent variables were studied. This result was achieved, in the eight weeks the level of anxiety decreased due to physical exercise intervention in the experimental groups. The third hypothesis showed that using analysis of variance of the dependent variable, there is no significant difference between the mean of experimental groups.

Table 4. The statistical indicators of non experiment group TAl

\begin{tabular}{|c|c|c|}
\hline & & \\
\hline Mathematical Mean & 52.94 & 53.83 \\
\hline Standard Error & 1.17 & .970 \\
\hline Standard Deviation & 4.96 & 4.14 \\
\hline Variance & 24.64 & 17.20 \\
\hline Minimum rate & 44 & 47 \\
\hline Maximum rate & 61 & 61 \\
\hline Variance 2 Measurements. & $F=11.206$ & $P<0.05$ \\
\hline
\end{tabular}

\section{Results}

Present findings of the assessment for the pre-test and post-test control group, showed no significant difference in first and final average. SD for group was 1.17 and 0.977 in $1^{\text {st }}, 2^{\text {nd }}$ measurements. In reviewing the status of students, did not make any difference for the control group, in the first test and second test. Then, trait anxiety rate dispersion was found a normal dispersion. The minimum score obtained for the control group, for the first measurement 44 and the second measurement is 47 . The rates obtained, indicates that there is no change in trait anxiety after 8 weeks.

Initial analysis of findings of the experimental group (bodily fitness), showed reduced trait anxiety in experimental group during (in pre test and post-test) the intervention period (Table $4 \&$ Table 5). Differences were obtained, the mean score of 59.7 for the first evaluation and the average score of 40.117 for the second evaluation, in group exercise (bodily fitness). With reducing the average rate of the first evaluation and

Table 5. Findings of exercise group (bodily fitness) 1. 2. assessment

\begin{tabular}{|l|l|l|}
\hline \multicolumn{1}{|c|}{ Statistical Indicators } & \multicolumn{1}{c|}{$\begin{array}{c}\text { 1.Anxiety } \\
\text { rate }\end{array}$} & 2.Anxiety rate \\
\hline Mathematical Mean & 59.76 & 40.11 \\
\hline Standard Error & 1.07 & .49 \\
\hline Standard Deviation & 4.42 & 2.05 \\
\hline variance & 19.56 & 4.23 \\
\hline Minimum rate & 52 & 37 \\
\hline Maximum rate & 68 & 43 \\
\hline Variance2. Measurements. & $\mathrm{F}=11.206$ & $\mathrm{P}<0.05$ \\
\hline
\end{tabular}

Sci.Technol.Edu.

CIndian Society for Education and Environment (iSee)

"Exercise for trait anxiety mitigation" http://www.indjst.org second evaluation, anxiety was reduced. There was a significant difference in trait anxiety of students in the experimental group bodily fitness, and this difference was significant between the first assessment and second assessment, $(P<0.05)$. It is meaningless to assume that it has emerged reduction in trait anxiety itself. Initial analysis of findings of the experimental group (aerobic program), showed reduced trait anxiety in experimental group during (in pre test and post-test) the intervention period. Differences were obtained, the mean score of 57.24 for the first evaluation and the average score of 40.47 for the second evaluation, in group exercise (bodily fitness). With reducing the average score of the first evaluation and second evaluation, anxiety was reduced. There was a significant difference in trait anxiety levels of students in the experimental group (aerobic program), and this difference was significant between the first assessment and second assessment, $(P<0.05)$. It is meaningless to assume that it has emerged reduction in trait anxiety itself (Table 6).

The first hypothesis detected that non-significant

Table 6. Findings of exercise group (Aerobic) 1. 2. Assessment

\begin{tabular}{|l|l|l|}
\hline \multicolumn{1}{|c|}{ Statistical Indicators } & 1. Anxiety rate & 2. Anxiety rate \\
\hline Mathematical Mean & 57.24 & 40.47 \\
\hline Standard Error & .816 & .89 \\
\hline Standard Deviation & 3.36 & 3.69 \\
\hline variance & 11.31 & 13.64 \\
\hline Minimum rate & 51 & 33 \\
\hline Maximum rate & 64 & 47 \\
\hline Variance 2 Measurements. & $\mathrm{F}=11.206$ & $\mathrm{P}<0.05$ \\
\hline
\end{tabular}

differences would appear among mean scores for the two exercise interventions and the control group in the beginning, as a consequence of randomized assignment to the three groups. The hypothesis was tested using a multivariate analysis of variance for, trait anxiety measures at beginning. Sk and kurtosis was within the range of -2 to 2; kurtosis of the pre test groups for female, was -1.414 kurtosis of the pre test groups for males was .801.Box's. Levene's test of equality of variances showed non-significant $(p<0.05)$ differences among the three groups' variances on each of the three pretest scores, showing that variances were same. Therefore, the information appears to meet the assumptions for multivariate analysis. Thus, randomization resulted in equality of means across groups in beginning. However, because inspection of the comparisons across groups for each dependent did not reveal some differences, for anxiety (trait), two the group's differences resulted in a significant $(p<0.05)$ affect, $F(91.41)$. The LSD post-hoc contrast didn't indicate significant $(p<0.05)$ differences

R.K.Shirifard \& H.Honari Indian J.Sci.Technol. 
between the bodily fitness with aerobic program group means.

Discussion

In this investigation, three hypotheses were tested. The first hypothesis detected no significant differences between groups at first. It was proposed in the second hypothesis that the two exercise interventions would be significantly more effective in reducing trait anxiety than would the non-exercise control group. And the third hypotheses didn't detect different mean between aerobic program and bodily fitness. It was hypothesized that each variable would demonstrate significant by group interaction effects. It was proposed that all two exercise interventions would show a stronger effect over the course of the eight weeks than the control (non-active control) group. This hypothesis was confirmed for anxiety (trait). Post-hoc analysis didn't reveal a significant contrast between the aerobic program and the bodily fitness group. At pretest there were no overall differences between groups. Same to it, eventually, there were not significant group effects for anxiety (trait). The only significant post-hoc comparison was for the time by group interaction effect, for the contrast between two exercise groups and the control group. The bodily fitness playing group's mean was 19 lower than the control group. All two had significant group effects, and in both cases, bodily fitness and aerobic program had the same score, and indicating less anxiety (trait) therefore it result the same well-being. In this case Post-hoc analysis showed that aerobic program had not lower means than of the other group. These findings indicate that the aerobic program intervention was not in its way inherently different than the other exercise group.

\section{Summary and conclusions}

Of course, if this study is to be conducted with larger groups, it will explore more robust statistical results. Posthoc analysis did not show some differences between exercises groups, and it may not be that the aerobic and bodily fitness intervention was different from the other. Research in other age groups, can reveal more angles. The study helps youths tap the beneficial aspects of exercises.

\section{References}

1. Bahrke MS and Morgan WP (1978) Anxiety reduction following exercise and meditation. Cognitive Therapy \& Res, 2, 323-333.

2. Barlow and David H (2002) Unraveling the mysteries of anxiety and its disorders from the perspective of emotion theory. Am. Psychologist. 55(11), 1247-63.

3. CDC (1996) Physical activity and health: a report of the surgeon general. US Department of Health and Human Services, National Center for Chronic Disease Prevention and Health Promotion, Atlanta.

4. Smith RE (1989) Conceptual and statistical issues in research involving multidimensional anxiety scales. $J$. Sport \& Exercise Psychol. 11, 452-457.
Vol. 5 No. 4 (Apr 2012)

ISSN: 0974- 6846

5. Spielberger CD, Gorsuch RL and Lushene RE (1970) STAI Manual for the State-Trait Anxiety Inventory ("Self-Evaluation Questionnaire") Palo Alto, CA.

6. Steinberg and Sykes EA (1985) Introduction to symposium on endorphins and behavioural processes: a review of literature on endorphins and exercise. Pharmacol. Biochem. Behaviour. 23, 857862.

7. Sonstroem RJ (1978) Physical estimation and attraction scales: rationale and research. Med. \& Sci. in Sports. 10, 97-102.

8. Sharon A. Plowman and Denise L. Smith (2007) Lippincott Williams \& Wilkins. p. 61. Retrieved 13 October 2011. 